\title{
Brazilian Micro-enterprises: An Exploratory Study on Marketing Strategies
}

\author{
Edmir Kuazaqui \\ Escola Superior de Propaganda e Marketing (ESPM), São Paulo, Brazil \\ Universidade Paulista (UNIP), São Paulo, Brazil
}

\begin{abstract}
This article aims to present the main marketing concepts applied by Brazilian micro-enterprises within a brief contextualization of a marketing plan. The methodology involved qualitative research development applied at the Trianon Fair, traditional event on Sundays on the sidewalks of the AvenidaPaulista in the city of São Paulo. Another research was carried out involving non-probabilistic sample with micro-businesses from various segments in the city that were chosen for their accessibility. From the results, product characteristics were elaborated, pricing, and distribution, that compose the application analyses of the marketing tools for micro-businesses and theoretical evolution have stemmed from the bibliographical research as well as field research and observational studies by the authors of the article. The goal is not to exhaust the topic nor to construct a Marketing Plan, but rather to contribute to the discussion, learning, and use of a marketing mix in the segment of micro-enterprises in a more assertive manner. It was concluded that there is no doubt as to the importance of micro-enterprises for any country. His contribution lies mainly in optical innovation and creativity because these companies can test new models of work, management, products, and services. It should be noted that micro-enterprises are greatly responsible for job generation in our country, denoting their prominent social and ecological perspective. More than a transient way of earning money, the reality of micro-enterprises should be considered as a social and economic phenomenon capable of generating regional and, consequently, global growth.
\end{abstract}

Keywords: micro-businesses, marketing, marketing mix, marketing strategies, consumer market, product

\section{Introduction}

Companies offer important contributions to society. Under an economic point of view, they contribute to the generation of income and, consequently, to the development which it unfolds. Under a social point of view, they enable, from economic development, the democratization of opportunities and improvement of the population, which then may have access to schooling and education. Finally, under an entrepreneurial point of view, there is the possibility of undertaking, creating, and innovating.

Kraus, Harms, and Fink (2010) gave evidence of the great contribution of small businesses in the generating of new ideas, products, service, and transactions, seeing that they generally stem from a more entrepreneur vision with possibilities for being able to use creativity and innovation in a more rapid manner.

Edmir Kuazaqui, Ph.D., Escola Superior de Propaganda e Marketing (ESPM); Management and International Marketing Department, Universidade Paulista (UNIP).

Correspondence concerning this article should be addressed to Edmir Kuazaqui, Universidade Paulista (UNIP), São Paulo, Brazil. E-mail: ekuazaqui@uol.com.br. 
Micro-enterprises are inserted in this context, but with differentiated features and contributions, by virtue of their size and dynamics. One of the great difficulties of this type of company is to be inserted and develop in the market due to income limitations that influence the budget and in the marketing intensity. In this way, communication dynamics and marketing strategies are differentiated in relation to medium and mainly large companies.

This article aims to present the main marketing concepts applied by micro-enterprises within a brief contextualization of a marketing plan. It has secondary objectives that look to identify how Brazilian micro-businesses can apply the marketing mix strategies (product, price, market, and distribution) as well as, a knowledgeable level of the management tools. The development and theoretical evolution stem from a bibliographical research, as well as a field and observational research by the author of this article. The goal is not to exhaust the topic, nor construct a marketing plan, but rather to contribute to the discussion, learning, and use of a marketing mix in the segment of micro-enterprises in a more assertive manner. And how can one make this plan work?

According to the Subcommittee Cabinet for Legal Affairs of the Presidency of the Republic (2013), micro-enterprises or small businesses are considered to be the business society, the simple society, the individual limited liability company.

The performance of Brazilian economy has offered, in the last decade, the emergence of micro and small enterprises (MPSs) to meet the growth in the production of goods and the provision of services. And, thus, requires tools that can offer stability and market growth. In this case, marketing comes to meet those needs.

\section{Methodology}

The classification of the research conducted, according to Marconi and Lakatos (2009), is qualified in as to purposes and as to means. As for research purposes, it was exploratory and descriptive. Exploratory, because they have not yet found the existence of any other studies on the subject and descriptive, because their aim was to describe the degree of knowledge of micro-entrepreneurs with regard to tools and marketing strategies.

To analyze the knowledge level of the tools and marketing strategies, research was carried out at the Trianon Fair that is help on Sundays on the sidewalks of the Avenida Paulista in the city of São Paulo, and has an average of 160 stalls. It is one of the more traditional regions where its history goes back to the late 1970's, and for this reason we chose to study it. A questionnaire applied there was duly registered and analyzed, with both open and closed questions, with the intent of raising administrative issues and other information related to the exhibitors.

Another research was carried out. Where the sample was composed of micro-businesses from various segments in the city of São Paulo, totaling 127 that were chosen for their accessibility, because as Marconi and Lakatos (2009) applied sample non-probabilistic. From the results, product characteristics were elaborated, pricing, and distribution, that compose the application analyses of the marketing tools for micro-businesses.

\section{The Marketing Plan and Consumer Market}

No company can survive without a good marketing plan. This means that any entrepreneur who wants to get the best results must be clear as to what market needs it will attend and how it will be done. The financial flow that will make it possible to meet the needs of the company and, at the same time will ensure sustained growth, will be thus obtained from the offer of a package of recognized benefits. 
Within this perspective, the starting point for the development of a strategic plan is the limitation of its powers through the creation of the mission, vision, objectives, and corporate values. After which, it is necessary to have the identified construction of a marketing mix that is able to meet, in a prompt manner, the various market needs.

Micro-enterprises, in Brazil, are generally born from different situations. One of the most common, being the loss of employment which makes the professional look for a short and medium term solution to balance personal cash flow. Another situation is when there is the unfolding of activities that a professional already exerts through outsourcing; another, still, stems from the profile of the entrepreneur himself, being the normal succession process, from father to son, in small businesses. In addition to this, Carlson (1985) already stated that the great differentiator between small, medium, and large businesses is their resources, where the small ones have limitations as to generating financial resources for projects and consequently a sustained manner for expansion. Thus, it is understandable that small businesses do not have a more elaborate clear strategic planning, but it is unacceptable that they accommodate themselves and work without a good business and marketing plan. Without a good marketing plan, the company will be able to get results, but without the certainty of measurable results; with one, the company will be able to obtain results in a manner which is more organized and manageable.

\section{The Consumer as the Primary Focus of the Company}

Every business starts from what the market can offer in terms of business opportunities. In this way, every organization must be created from the meeting of the needs and desires of the market. The term consumer can be defined as everyone who can buy, rent, use or take advantage of a product or service offered by a company or professional. According to Foxxall (Baker, 2005, p. 87), "the consumer decision-making process is usually described as cognitive. The consumer is aware of a need or desire and a possible means to satisfy it, normally announced in the advertisement of a new brand".

In general, as consumers are spread out over the market, one of the major initial difficulties of the microenterprise is the limitation of its scope. Such companies usually grow from regional demands, promptly meeting determined consumer needs. And, as the offer of products and services is done by different sized companies, micro-enterprises come up against some difficulty in facing the marketing appeals that the medium and large sized companies make. On the other hand, Hawkins, Mothersbaugh, and Best (2007) stated that:

The most obvious result of the process for an individual consumer, whether the purchase is carried out or not, is some level of need satisfaction that initiated the process of [...] Two fundamental processes are involved-the real need satisfaction and the perceived need satisfaction. (p. 17)

Even with all the limitations, micro-enterprises should be attentive to consumer behavior, which can have great mobility and contact with different companies of different sizes. So, one of the ways of survival for these companies is the use of long- and short-term incentives which will be dealt with later.

One of the biggest challenges is that consumers make their first purchase and then repurchase, thus becoming a client. A client is anyone who has a link, sometimes with a company or a professional. In this context, marketing categorizes two levels of clients:

- Internal customer or internal public, which boils down to the company's employees. In this sense, marketing strategies as internal marketing serve as actions that target their involvement and commitment with the objectives and goals of the company; 
- External client, which is characterized as one who will purchase the product or service. The enterprise should measure their quantitative and qualitative demand. The first will provide a consumer perspective and the second the profile, which will shape the company's marketing strategies.

\section{Market Segmentation as the Main Strategy for Micro-enterprises}

Due to its peculiarities, such as limitation of resources and geographic reach, it is recommended that micro-enterprises promptly use the market segmentation strategies. Under the context of marketing, market segmentation technique considers the characteristics of the market where the company wants to work of extreme value. The market segmentation advocates the idea that the market is heterogeneous with regard to its characteristics and consequent needs, desires, and aspirations. In this way, the segmentation technique requires the identification and measurement of differences and groups them into consumption categories. There are three ways to categorize market segmentation strategies:

- Undifferentiated marketing strategy considers the market to be homogeneous with respect to its characteristics and needs. The company can offer a marketing mix without any differentiation. Considering Maslow's Theory, one can employ this strategy for products and services that meet basic needs such as water, for example, and the provision of general services;

- The concentrated marketing strategy considers that the market may have special features that the company can meet. In this way, it can focus its efforts on a single market segment. In this case, regionalism anticipates itself as one of the key variables, as well as special features and characteristics of where the company is located; and finally;

- Differentiated marketing strategy, in which the company identifies segments where they want to act and develops a marketing mix directed at each one of them. In this case, the company has a portfolio of strategies for each type of client group.

The selection of the best segmentation strategy involves:

- On the part of the company it allows for the optimization of economic, financial, and human resources, involving any of the above strategies. There is no differentiation; there is the possibility of bargaining power due to the volumes transacted. If differentiated, it enables the purchase of lots that are compatible with the demand;

- On the part of the demand there is the option for the product or service that best meets your needs, then loyalty may occur and consequently the periodic purchasing of lots.

Market segmentation stems from the needs of the business and its good service towards the costumers, which makes it a form of sustained customer loyalty; on the other hand, if all companies think the same way, the same strategies become forms of competitive differentiation. Baker (2005, p. 44) stated that segmentation: "[...] is not only dynamic and uncertain, but also diverse: enterprises are heterogeneous, as well as the nature of the demand".

One can categorically state, however, that one of the main marketing techniques that an enterprise can apply and from where there will be a more effective return is market segmentation, because:

- The company, with detailed knowledge of the market, can better understand their characteristics, needs, and deficiencies. From the understanding of quantitative and qualitative characteristics, it is possible for a referential analysis;

- From the correct interpretation of data and information, the company should formulate the best marketing 
mix in a way that so promptly meets and sustains the segment you want to reach. Through the very essence of the marketing system, the marketing mix is a reflection of the characteristics of market potential;

- According to the demand and offer, it enables the measurement, optimization, and management of resources to better attend the segment, in view of the needs of the enterprise itself;

- Allows for more flexible strategies according to the possible changes, even if they be quick and subtle, this and other complementary niches.

The application of information systems, essentially—Information Systems in Marketing and Market Research - it is primordial for the identification of market niches and their characteristics and needs that should be met. Market research identifies quantitative and qualitative demand, referencing market potential. In turn, marketing information systems provide data and feedback information from secondary data. The updating of data and information is important to give the company the basic elements for the adequacy of marketing strategies according to the life cycle of the product (PLC) or service to be analyzed. Although micro-enterprises have limited resources, it is understood that they can use the systems in a prompt manner, with the use of secondary data from trusted sources.

The customer base of a company can be categorized according to the consumption profile of their active clients:

- A portfolio with light users: customers that buy small volumes. They bring great operational costs and contribute little individually in relation to the working capital needs of the company. However, they can ensure the maintenance of the business, if grouped properly. A small cafeteria can have a daily volume of income from the clients of the famous coffee break;

- A portfolio with medium users: customers that buy periodically and in a certain volume. A restaurant per kilo can diversify its menu periodically to maintain its customers;

- A portfolio with heavy users: customers that buy large volumes, but without any frequency. The company must be prepared to meet large batches and consequently cope with stock costs. A company can take advantage of small business opportunities, but should focus on specific events, such as graduations, graduate programs, which bring in high income every six months, enough to meet the needs of the working capital for the whole year.

If a company adopts a mixed strategy, it should make its services compatible in such a way as to attend to all classes of customers. A small business, for example, must have a diverse portfolio of clients with different contributions. In this case, it should make its resources compatible and have good management and control tools.

\section{The Marketing Mix of Micro-enterprises}

The survival of a company is directly related to the acceptance, on the part of the consumers, of that which it offers to the market. McCarthy and Perreualt (1999, p. 43) mentioned that the marketing compound is the set of "controllable variables that the company gathers to satisfy this target group" (consumers). These controllable variables, also known as marketing mix, can be categorized as the four Ps: product, price, promotion, and distribution points. The company should generally offer a mix that offers solutions for the needs of its consumers. On the other hand, the market should reciprocate the offer of solutions through payments that ensure the sustainability of the company.

Also, as controllable variables, aside from the internal environment, there are the raw material suppliers 
and services, competitors, and distributors, which will be analyzed in conjunction with the analysis of the marketing mix. We decided to also avoid macro environmental analysis, which can be categorized as an uncontrollable variable, such as the economic, technological, and demographic environment, among others. In this way, we maintain the focus in the marketing mix. The first to be examined will be the product.

\section{Product}

In a marketing mix there is what is offered to the market in material form. Kotler and Armstrong (2008) as the basis for all the marketing compound, define:

[...] a product as something that can be offered to a market for assessment, acquisition, use or consumption and that may satisfy a desire or need. Products include physical objects, services, events, people, places, organizations, ideas or a mixture of all of these entities. (p. 200)

Micro-enterprises have characteristics and particularities that influence the product offered, as in Table 1.

Table 1

\section{Product Features}

\begin{tabular}{|l|l|l|}
\hline Item reviewed & Particularity & Analysis and recommendation \\
\hline $\begin{array}{l}\text { Raw material } \\
\text { suppliers and } \\
\text { services }\end{array}$ & $\begin{array}{l}\text { For having limited financial and economic resources, the } \\
\text { company may find it difficult to acquire raw material or } \\
\text { services at competitive prices. }\end{array}$ & $\begin{array}{l}\text { You can choose the purchasing cooperatives, where } \\
\text { the same raw materials can be purchased in volume } \\
\text { and increasing bargaining power with suppliers. }\end{array}$ \\
\hline Production & $\begin{array}{l}\text { The company may have difficulty producing or simply } \\
\text { selling in large quantities. }\end{array}$ & $\begin{array}{l}\text { Can try outsourcing processes and focusing on its } \\
\text { customer base. }\end{array}$ \\
\hline Distributors & $\begin{array}{l}\text { The company usually sells its products in a regional } \\
\text { fashion, within its reach capacity. }\end{array}$ & $\begin{array}{l}\text { Can try negotiating, concentrating intensively on the } \\
\text { distribution of what it sells. }\end{array}$ \\
\hline Competitors & $\begin{array}{l}\text { The company may have different types of competition, } \\
\text { according to their specific characteristics, such as size and } \\
\text { composition of what is sold. }\end{array}$ & $\begin{array}{l}\text { Aggressive monitoring should be drawn up in } \\
\text { relation to direct and indirect competitors. }\end{array}$ \\
\hline
\end{tabular}

Note. Source: Authors.

In this way, the micro-enterprises should look for alternatives in order to increase sales through the increase of its production capacity and, consequently, their productivity and scale economies. There are two crucial points to enable growth in a sustained manner:

- Obtaining productivity and scale economies means increasing one's financial return and decreasing costs and expenses;

- Obtaining competitive differentiations through gradual innovations. Small businesses must provide products or services to the market, despite their research and development limitations. The innovations coming from small businesses can represent a way to decentralize power-which is naturally centered on large companies.

A good example is the strategy of an Excel spreadsheet, which is part of a Windows package. This spreadsheet was previously known as Lotus and the company that developed it, did not have the resources to market it internationally. They decided then for patent registry and concession to Microsoft. In this way, the product could be marketed globally, regardless of the size and resources of the company concerned.

A solution for the lack of resources to be adopted by micro-enterprise is building on provision of financial resources by entities such as the National Economic and Social Development Bank, The Brazilian Development Bank (BNDES), as well as the guidance of entities such as the Brazilian Service of Support for Micro- and Small-Enterprises, SEBRAE. In addition, higher education institutions, through their junior 
companies and incubators, can become paths for innovating products and services and for business management itself.

Below, the distribution channels will be analyzed with a more organic viewpoint.

\section{Relationship Channels}

From the perspective of a marketing mix, there are also distribution channels, which initially may be defined as entities that provide the exchange between manufacturers and consumers. However, in a more organic vision, these entities have different and important roles in the process of exchange. According to Kotler and Armstrong (2008):

Generating a product or service and making them available to buyers requires building relationships not only with customers but also with suppliers and salesmen in the supply chain of the company. This consists of supply chain partners “at levels above” and "levels below”. (p. 304)

On the level above are the suppliers, and the distribution channel represented by wholesalers and retailers are on the level below. According to the number of participants, there are the following levels:

- Zero-level—characterized by direct marketing with the client. In this case, the company can get better financial returns for not having distribution and marketing expenses, but must absorb the transaction and operational costs;

- Level one-there is the presence of retailers, which can be defined as specialized agencies in trading and transactions that increase the reach of the company within the consumer market;

- Level two - there is the presence of wholesalers that buy in bulk and resell to retailers and/or end customers. Generally, there is little possibility of operation by micro-enterprises at this level, due to production limitation, except for negotiations and specific contracts.

However, every company needs to have an integrated view of its business, as well as what each entity aggregates in relation to the value perceived by consumers.

Table 2

Distribution Characteristics

\begin{tabular}{|l|l|l|}
\hline Item reviewed & Particularity & Analysis and recommendation \\
\hline Transacted volumes & $\begin{array}{l}\text { The company has no bargaining power with the } \\
\text { distribution channel. }\end{array}$ & $\begin{array}{l}\text { The company can choose for a negotiation that } \\
\text { facilitates more effective frequency at the expense of } \\
\text { increased cost, distribution, and marketing expenses. }\end{array}$ \\
\hline Logistics & $\begin{array}{l}\text { The company may have difficulty in receiving, } \\
\text { stocking and marketing the product. }\end{array}$ & $\begin{array}{l}\text { Must have a management that enables rational } \\
\text { planning stemming from its limitations. }\end{array}$ \\
\hline
\end{tabular}

Note. Source: Authors.

Distribution strategies can be categorized into intensive, selective, and exclusive:

- Intensive distribution strategies imply strong distribution capability throughout the market and with great geographical reach. For reason of their limitations, micro-enterprises are unable to achieve this level of intensity;

- The strategies of selective distribution indicate that the company may choose certain dealers, according to their production limitations, as well as their access to different categories of consumers;

- Exclusive distribution strategies indicate that the micro businessman has chosen a company category for the marketing of their produce, which gives them better control and focus on their sales.

Companies in the area of food products, for example pizzerias, have bypassed geographical limitations by 
means of outsourcing their deliveries. Another important factor is the possibility of geographic dispersion. A good example is the Giraffe's, which has obtained considerable growth and is also present internationally.

In recent times, logistics areas-internal and external—and physical distribution have become one of the greatest objects of analysis. It is of no value having a good product if it is not open to distribution or if there be any delay in delivery. The solution for micro-enterprises is sound management through the creation of indicators. If on the one hand, the introduction of management indicators, such as the Balanced Score Card (BSC), can initially generate barriers, due to the standardization of procedures and processes; it will allow the company to have a more complete vision of the business, as well as, the relationship channels.

Following below are the tangible products pricing strategies.

\section{Initial Pricing Concepts}

Every company must charge for what it offers to the market; all consumers must pay, and understand that they are getting something of a particular value. Thus, Kotler and Armstrong (2008) noted that:

In the strictest sense, price is the amount you will charge for a product or service. More widely, the price is the sum of all the values that consumers exchange for the benefits of getting or using a product or service. Historically, the price has been the main factor that affects the buyer's choice. (p. 258)

The formation of the price for the final consumer is one of the hardest decisions in the marketing compound, since it involves different variables that small business people are sometimes not aware of. It can and must involve aspects related to production and marketing costs, fixed and variable, and profit margin, i.e., should be contextualized with the chain of values and corporate objectives of the company. Supplementing with McCarthy and Perreualt (1999, p. 275): "price objectives should flow and be adjusted to the company and their marketing goals. It should be explicitly declared because they have a direct effect on price policies, as well as the methods used for their determination".

According to the strategic planning of a company, the strategies of pricing can be:

- Elite or creaming method, in which the company offers to the market a product or service at a high price, being understood that this has a high added value, and that there is a consumer market interested and with sufficient income;

- Floor or introduction, in which the company offers something at a low price, considering that the product or service does not have sufficient attributes that lead consumers to pay a higher price for it.

The selection of price strategies stems from several situations involving: the categories of products and services offered, competition, suppliers, level of competition and expectation of returns on initial investment and working capital. In most cases, micro-enterprises offer a product or service at a competitive level, concerned mainly with short-term return.

In sequence and terminating the analysis of the mix, the various forms of communication, information and promotion of their businesses, companies, products, and services.

\section{Promotion Tools for a Micro-enterprise}

To inform and market their products and services, all companies must use a composite of promotion. According to Kotler and Armstrong (2008):

Building good relationships with the client requires more than just the develop of a good product, giving you a competitive price and making it available to the target customers. Companies also need to communicate their value propositions to customers. (p. 357) 
The promotion compound is formed by long- and short-term incentives in order to motivate consumers into buying products and services at that time, but also aiming at managing the beginning and promoting the maintenance of the business relationships. Long-term incentives may be advertising and public relations; and short-term incentives can be categorized as sales promotion and personal selling.

Table 3

Characteristics and Applications of the Compound of Promotion

\begin{tabular}{|l|l|l|}
\hline Composite item & Particularity & Analysis and recommendation \\
\hline Advertising & $\begin{array}{l}\text { Long-term stimulus that aims to inform and } \\
\text { generate relationships, especially with the } \\
\text { target audience. Usually using printed, } \\
\text { virtual, and electronic media. }\end{array}$ & $\begin{array}{l}\text { Because of the cost and breadth, in general, the } \\
\text { microenterprise ceases to opt for this alternative of promotion } \\
\text { or even the option for a more regionalized vehicle, such as } \\
\text { neighborhood newspapers and similar means. }\end{array}$ \\
\hline Public Relations & $\begin{array}{l}\text { Long-term stimulus that aims at generating } \\
\text { relationships with different public, including } \\
\text { the target market. With such tools as news } \\
\text { and press releases. }\end{array}$ & $\begin{array}{l}\text { Because of the diversity of ways to generate the stimuli, it can } \\
\text { be an important tool of exposure with the public nearest to the } \\
\text { company. }\end{array}$ \\
\hline Sales promotion & $\begin{array}{l}\text { Short-term stimuli, aimed at transforming } \\
\text { the action in selling, such as discounts, } \\
\text { promotional packages, among others. }\end{array}$ & $\begin{array}{l}\text { It is one of the most suitable stimuli for small firms, for } \\
\text { facility reasons and for not having high developmental costs. }\end{array}$ \\
\hline Personal selling & $\begin{array}{l}\text { Short-term stimulus that aims at contributing } \\
\text { towards more forceful sales. }\end{array}$ & $\begin{array}{ll}\text { It is one of the most commonly used stimuli by small } \\
\text { businesses, by the very nature of its operations. }\end{array}$ \\
\hline
\end{tabular}

Note. Source: Authors.

Micro-enterprises should combine the different actions in accordance with their goals and objectives, as well as in accordance with their expectations and budget. In general, the company must therefore generate long-term incentives, disclosing their name and promoting their respective products and services. In addition, short-term stimuli should be promoted in order to render sales and have the consequent return on their investment. In the specific case of micro-enterprises, it is natural for them to make greater use of short-term incentives because of their need for financial return.

One option is the use of the internet to disseminate the company, as well as for marketing and the sale of its products and services. Lodish, Morgan, and Kallianpur (2002) recalled the importance and relevance of the web in business enterprises and viral marketing.

Some companies can get free exposure by yielding part of their products and services. It is natural for restaurants to give amenities in exchange for exposure in newspapers and magazines. According to the methodology mentioned, some research was carried out the by author together with Kuazaqui, Lisboa, and Silva (2011), with the purpose of identifying the knowledge level of the management tools, as shown in Table 4, as well as those related to marketing strategies.

Table 4

Administrative Skills

\begin{tabular}{|c|c|c|c|c|c|c|}
\hline Instrument & Know & $\%$ & Unaware & $\%$ & Total & $\%$ \\
\hline Cash flow & 35 & 48.61 & 37 & 51.39 & 72 & 100.00 \\
\hline Selling price & 56 & 77.77 & 16 & 22.23 & 72 & 100.00 \\
\hline Sales techniques & 66 & 91.66 & 06 & 8.34 & 72 & 100.00 \\
\hline Accounting & 15 & 20.83 & 57 & 79.17 & 72 & 100.00 \\
\hline Marketing & 27 & 37.50 & 45 & 62.50 & 72 & 100.00 \\
\hline Legal & 18 & 25.00 & 54 & 75.00 & 72 & 100.00 \\
\hline Total & 217 & & 215 & & & \\
\hline
\end{tabular}

Note. Source: Kuazaqui, Lisboa, and Silva (2011, p. 7). 
Such ignorance on the part of micro entrepreneurs derives from various reasons, having as the main factor a lack of administration and marketing training, as well as in specific management areas. Adding to this reality, as was testified by Carlson (1985), the micro-businesses also have limited resources, which can hinder their growth in a sustainable way. Completing the analysis of the marketing mix, small businesses should look at their resources and possibilities for expansion and growth through the characteristics of the market in which they wish to act. Administration and management of resources with an integrated view of the market can provide the company with a clearer vision of the future, making for stronger strategic planning and ensuring its sustainability.

Concluding the article, marketing trends will be briefly analyzed with focus on social responsibility and sustainability.

\section{Marketing Trends for Micro-enterprises}

Micro-enterprises contribute significantly to national economy, but they are influenced by external variables, such as the international, economic, social, technological, demographic, geographic environment, among others.

According to the Brazilian Service of Support for Micro and Small Businesses (SEBRAE) the number of micro-enterprises in the country has grown which also denotes a certain level of entrepreneurship. SEBRAE is a private non-profit organization established in 1972. It aims to promote competitiveness and sustainable development of micro and small enterprises. Maybe there would be a fewer number of new small businesses, if the opening decision involved only the financial aspects and equipment; but the entrepreneurial spirit drives the entrepreneur to think differently and adds more power to one's business. As direct consequences, there is the generation of new posts of employment that comprehend direct social gain, aside from the possibility of the creation of new technologies and innovation. Oliveira (2008) stated that:

The field of corporate social responsibility is not only for multinational companies that have global impact. Small companies have important economic activities at the local level in many parts of the world. In addition, many have a very close relationship with the company, investing in social projects, even if they are not recognized as social responsibility actions. (p. 3)

In counterpoint, Ghemawat (1999) developed an interesting theory about management from the use of resources (be they limited or not) for sustained growth. Finally, we highlight here, a text from "GuiaExame" (2011), according to which:

Around the world, the quest for a more sustainable economy became one of the great hopes for the resumption of growth. New technologies will need to be created, production methods will have to be reviewed and it is possible that the way we deal with natural resources will go through a radical change. Where will innovation blossom? It is hard to say. If the example of the technological revolution is repeated, many of the novelties will come from new companies, generated by visionary entrepreneurs. It is this, in addition to other factors that are uniting small companies with sustainable appeal and large businesses interested in improving their own performance indicators, in social and environmental areas. (p. 88)

In this way, one can understand the current importance of micro-enterprises and their significance in a wider context, visionary and within the perspective of integrated social responsibility and environmental sustainability. 


\section{Final Considerations}

There is no doubt about the importance of micro-enterprises for any country. Their contribution lies mainly in the economic and social insertion. It should be noted that micro-enterprises are the main ones responsible for the generation of employment in our country, denoting their prominent social and ecological perspective.

As part of their nature, micro-businesses have limited resources, highlighting financial and personnel, impacted by the bargaining power together with their suppliers and distributors, as well as their capacity to offer their products or services in a more aggressive manner to the consumer market, once they do not have the necessary transaction volumes so as to obtain better business possibilities. Aside from this, the entrepreneurs are deficient as to management knowledge and the respective assertive use of their instruments and management tools.

However, we can highlight the importance, aside from those referred to above, of the possibility of micro-businesses embarking on the use of creativity as a means of bringing about innovations that aim at developing necessary technology for society. The act of enterprising is extremely relevant, considering the possibility of creating new forms of regional businesses, as well as, future possibilities for internationalizing. In this way, it becomes necessary to have manager and collaborator professionalization in small businesses, whether by means of academic graduation or courses and specific training, that make management tools and marketing practices more competitive in relation to domestic and international markets.

More than a transient way of earning money, the reality of micro-enterprises should be considered as a social and economic phenomenon capable of generating regional growth and, consequently, global.

\section{References}

Baker, M. J. (2005). Marketing book (5th ed.). São Paulo: Campus.

Carlson, D. J. (1985). The evolution of marketing in small firms. European Journal of Marketing, 19(5), 7-16.

Exam Guide (2011). Sustainability. São Paulo: Editora Abril.

Ghemawat, P. (1999). Strategy and the business landscape. Porto Alegre: Bookman.

Hawkins, D. I., Mothersbaugh, D. L., \& Best, R. J. (2007). Consumer behavior (10th ed.). São Paulo: Campus.

Kotler, P., \& Armstrong, G. (2008). Princíples of marketing (12th ed.). São Paulo: Pearson.

Kraus, S., Harms, R., \& Fink, M. (2010). Entrepreneurial marketing: Moving beyond marketing in new ventures. International Journal of Entrepreneurship and Innovation Management, 11(1), 19-34.

Kuazaqui, E. (2007). International marketing: Building knowledge and skills in global scenarios. São Paulo: M. Books.

Kuazaqui, E., Lisboa, T. C., \& Gamboa, M. (2006). Marketing and strategic management for private and public companies. São Paulo: Nobel.

Kuazaqui, E., Lisboa, T. C., \& Silva, F. B. (2011). The contributions of the craft fairs in the city of São Paulo. Rio de Janeiro: SEGET.

Lodish, L., Morgan, H. L., \& Kallianpur, A. (2002). Entrepreneurial marketing. São Paulo: Campus.

Malhorta, N. (2009). Basic marketing research: A decision-making approach (3rd ed.). São Paulo: Pearson.

Marconi, M. A., \& Lakatos, E. M. (2005). Fundamentals of scientific methodology (6th ed.). São Paulo: Atlas.

McCarthy, E. J., \& Perreault, W. D. (1999). Essentials of marketing. São Paulo: Atlas.

Oliveira, J. A. P. (2008). Business in society: Sustainability and social responsibility. São Paulo: Campus.

Serviço Brasileiro de Apoio às Micro e Pequenas Empresas (SEBRAE). (2013). Retrieved February 13, 2013, from http://www.sebrae.gov.br

Subcommittee Cabinet for Legal Affairs of the Presidency of the Republic. (2013). Retrieved February 13, 2013, from www.planalto.gov.br/ccivel_03/leis 